Western University

Scholarship@Western

$1-27-2019$

Evaluating knowledge of falls risk factors and falls prevention strategies among lower extremity amputees after inpatient prosthetic rehabilitation: a prospective study

Susan W. Hunter

Jordan Higa

Courtney Frengopoulos

Ricardo Viana

Michael Payne

Follow this and additional works at: https://ir.lib.uwo.ca/ptpub

Part of the Physical Therapy Commons 


\section{Evaluating knowledge of falls risk factors and falls prevention strategies among lower extremity amputees after inpatient prosthetic rehabilitation: a prospective study}

Susan W Hunter, ${ }^{1,2}$ Jordan Higa, ${ }^{3}$ Courtney Frengopoulos, ${ }^{3}$ Ricardo Viana,${ }^{2,4}$ Michael WC

Payne ${ }^{2,4}$

1.School of Physical Therapy, University of Western Ontario, London, ON, Canada. 2. Schulich School of Medicine \& Dentistry, Department of Physical Medicine and Rehabilitation, University of Western Ontario, London, ON, Canada. 3. Faculty of Health and Rehabilitation Sciences, University of Western Ontario, London, ON, Canada. 4. Department of Physical Medicine and Rehabilitation, Parkwood Institute, London, ON, Canada.

Corresponding author:

Dr. Susan W Hunter

University of Western Ontario

School of Physical Therapy

Room 1588, Elborn College

1201 Western Road, London, Ontario

Email: susan.hunter@uwo.ca

Telephone: 519-661-2111 ext88845

Funding: This work was supported by the St. Joseph's Healthcare Foundation Cognitive

Vitality and Brain Health Seed Funding Opportunity in London, Ontario, Canada. The

funding body had no involvement in the conduct of the study.

Conflict of interest: The authors have none to report. 


\title{
Evaluating knowledge of falls risk factors and falls prevention strategies among lower extremity amputees after inpatient prosthetic rehabilitation: a prospective study
}

\begin{abstract}
Purpose: Falls are prevalent among people with lower extremity amputations. A knowledge of risk factors is important in preventing falls, though no research has evaluated patient understanding of falls in this population. The study objective was to evaluate knowledge of falls risk factors and falls prevention strategies at discharge and 4-months after inpatient prosthetic rehabilitation.
\end{abstract}

Methods: Participants completed four questionnaires on: 1) falls during rehabilitation and after discharge, 2) falls self-efficacy using the Activities-specific Balance Confidence scale, 3) knowledge of falls risk factors, and 4) falls prevention strategies. Questionnaire responses were quantified using means and standard deviations or frequencies and percentages. Data were analyzed using paired t-tests for Activities-specific Balance Confidence scale and the knowledge of falls risk factors; and using chi-square analyses for fall prevention strategies. Results: Twenty-seven individuals (aged 62.55 $\pm 8.36 ; 55.6 \%$ male) were included. Unsafe or risky behaviours and not paying attention to surroundings were perceived as the top two falls risk factors. Although these factors are modifiable, only $5.9 \%$ of participants listed preventative behavioural modifications. No significant differences were found in Activitiesspecific Balance Confidence scale scores $(\mathrm{p}=.404)$ or knowledge of falls risk factors ( $\mathrm{p}=.361)$ between discharge and follow-up.

Conclusion: This study highlights a gap between knowledge of falls risk factors and application of knowledge to prevent falls. Follow-up data suggest that lived experience does not affect the knowledge of falls risk factors. 
Key words: amputation, falls, lower extremity, rehabilitation, fall prevention 


\section{Introduction}

Falls are very common for people with major lower extremity amputations at all stages of rehabilitation and over the long-term, after discharge to the community [1]. Falls occur most commonly while people are wearing their prosthesis and performing normal activities of daily living, such as walking [2]. Despite best efforts and functional gains in prosthetic rehabilitation programs, the falls risk of adults with lower extremity amputation exceeds that for frail older adults in the community [3]. Dite et al. [4] found that $42.5 \%$ of people with an lower extremity amputation fell in the first 6 months after discharge from inpatient rehabilitation. This exceeds the value for people with a stroke (23\%) and community-dwelling older adults $(33 \%)[1,5]$.

The consequences of falling are dire for people with an lower extremity amputation, including physical injury, fear of falling, lack of prosthesis use, social withdrawal and reduced quality of life [6,7]. A fear of falling, defined as an avoidance of activities that a person is capable of performing, occurs in $49.2 \%$ among people with an lower extremity amputees using a prosthesis [8]. The goals of prosthetic rehabilitation are to develop the ability to perform well in real-world situations. Falls have adverse consequences on these goals; therefore, knowledge of falls risk factors and awareness of falls prevention strategies are important in optimizing outcomes for community reintegration after an intensive prosthetic rehabilitation program.

There is a small body of literature on fall risk factors in people with a lower extremity amputation, but there are limited fall prevention intervention studies for this population to inform best-evidence practice. The success of current fall prevention education strategies, as evidenced by people's understanding of risk factors and implementation of prevention 
strategies, is also not known. The initial months after discharge from rehabilitation are a critical period in fall prevention as some activities cannot be fully approximated during a rehabilitation program. It is unknown whether exposure to normal daily activities after returning home affects people's strategies for preventing falls.

No literature exists in the lower extremity amputation population regarding knowledge of falls risk factors and falls prevention strategies in the post-discharge period; even among community-dwelling older adults there are gaps in the understanding of risks [9]. Importantly, the development of self-efficacy to initiate active strategies to reduce the risk of falling after discharge from inpatient rehabilitation may be facilitated if people with a lower extremity amputation have awareness and knowledge about falls and falls prevention strategies. In order to determine the educational requirements of this population, it is important to identify and describe strategies that people with a lower extremity amputation believe will reduce their risk of falls at the time of discharge from inpatient rehabilitation.

The objective of this study was to determine knowledge of falls risk factors and fall prevention strategies in individuals with a new lower extremity amputation at discharge from and 4 months after an inpatient prosthetic rehabilitation program. The objectives of this study were: 1) to evaluate the falls risk factors and falls prevention knowledge of individuals with a new lower extremity amputation at the time of discharge from an inpatient prosthetic program; and 2) to determine if there is a change in knowledge after four months of integration into usual living environment.

\section{Materials and Methods}

\section{Design and Participants}


This was a prospective cohort study of with a first major unilateral lower extremity amputation who completed the Inpatient Amputee Rehabilitation Program in xxxxxxxxx. Individuals were recruited between March 2016 and April 2017. This study was approved by the Health Science Research Ethics Board at XXXXX and by the Clinical Resources Impact Committee of XXXXXXXX. All participants provided informed consent.

Requirements for all admissions to the Inpatient Amputee Rehabilitation Program were: $\geq 18$ years old with a major lower extremity amputation, identifiable rehabilitation goals, medically stable, and mentally and physically ready to enter the comprehensive rehabilitation program. Inclusion criteria for the cohort study were: first major unilateral lower extremity amputation (i.e., trans-tibial or trans-femoral), age $\geq 50$ years, independent ambulation for 10 meters with or without mobility aid and without the assistance from another person. The exclusion criteria were non-ambulatory, non-English speaking, having severe cognitive impairment that limits the ability to follow instructions or provide informed consent. Those with Symes, hip disarticulation, partial foot, knee disarticulation or bilateral amputations were also excluded from the study. Individuals undergoing prosthetic rehabilitation for a first major unilateral lower extremity amputation were recruited prior to discharge.

While in the inpatient program, participants are provided context specific education regarding falls and fall prevention. They do not attend education sessions on falls prevention and are not provided with falls prevention handouts. However, the staff provide education regarding fall risk as well as extrinsic and intrinsic strategies for prevention. Early in the admission, participants review transfers without wearing a prosthesis, mobility and participation in activities of daily living activities. Nursing and allied health staff provide 
education regarding falls risk when moving between surfaces or during the activities. They also discuss strategies to avoid falls. During gait training, participants review proper transfer techniques with the prosthesis. Also, as they progress from using the parallel bars to gait aids, and progress from one gait aid to the next, participants discuss proper use of the aid, how to monitor safety and balance, and risk of falls with the various devices. Participants also begin to learn how to incorporate the prosthesis into functional mobility and activities of daily living. Participants and family members are also taught how to safely get up from the ground with and without wearing the prosthesis.

Lastly, prior to discharge, participants review functional tasks in the home environment, vehicle transfers, and ambulation in simulated outdoor environments. If needed, a home assessment was performed with equipment recommendations made and installed prior to discharge. Lastly, individuals participated in a therapeutic community outing prior to discharge to practice identifying obstacles in order to prevent falls.

\section{Demographics}

Demographic and medical history information were obtained including: age, sex, height, weight, years of education, level of amputation, etiology of amputation and comorbidities. The Montreal Cognitive Assessment was administered within 1 week of admission to provide a brief evaluation of cognitive functioning [10]. The MoCA is a reliable and valid screening tool that was developed to detect mild cognitive impairment. The test has a maximum score of 30 , with scores $\leq 25$ indicative of mild impairment in cognition $[10]$.

\section{Outcome Measures}


Participants completed a self-administered questionnaire that included 54 questions on falls. (See Appendix A for questionnaire items on falls). These were divided into 4 subsections: 1) falls during rehabilitation and after discharge, 2) Activities-specific Balance Confidence scale, 3) knowledge of falls risk factors and 4) falls prevention strategies. The questionnaire was administered at discharge from the rehabilitation program and at the regularly scheduled medical follow-up appointment 4-months after discharge.

\section{Falls During Rehabilitation and after Discharge (8 questions)}

Falls during rehabilitation and after discharge were assessed with yes/no questions regarding the occurrence of a fall. A fall was defined as "an unexpected event in which the participant comes to rest on the ground, floor, or lower level" [11]. Information was also collected on whether or not the fall resulted in an injury. Injurious falls were defined as any physical harm resulting from a fall self-reported by study participants. In the occurrence of an injury, information on where the injury occurred on the body, if medical attention was necessary, whether or not they were wearing their prosthesis and if the fall affected their confidence was collected. All participants were also asked, "Are you afraid of falling such that you have stopped doing activities you are physically capable of doing?".

\section{Activities-specific Balance Confidence scale (16 questions)}

The Activities-specific Balance Confidence scale is a 16-item self-report measure that assesses balance confidence in mobility-based tasks [12]. Confidence for each item is rated on a scale of $0 \%$ (no confidence) to $100 \%$ (completely confident) and the total score is an average of the 16 items [12]. The Activities-specific Balance Confidence scale has good internal consistency and test-retest reliability in this population [13].

\section{Knowledge of Falls Risk Factors (15 questions)}


Knowledge of falls risk factors was assessed using a questionnaire by Braun et al. [1] and the wording was modified for people with a lower extremity amputation. Participants were asked to rate how likely each of the 13 factors were to make an individual with a prosthesis fall, on a scale from 0\% (not likely) to 100\% (most likely). Four themes of risk factors were covered-interior environmental factors, exterior environmental factors, physical factors and psychological factors.

In this section participants were also asked, "At a guess, if you talked to 100 people one year after they had finished their rehabilitation for a prosthesis, how many do you think would have had at least one fall?". Participants were then asked whether or not they believe that falls among people with a lower extremity amputation using a prosthesis could be prevented.

\section{Falls Prevention Strategies (15 questions)}

Participants were asked to rate the importance of falls prevention compared to other health concerns on a scale of 0-10; 0 being not at all important and 10 being most important. Participants were asked if they believed they would suffer a fall within the 12 months following discharge home. Two questions were then posed: if they would be seriously injured by a hard fall and if they would be able to return to their current living situations after a hard fall. Responses were recorded using a 5-point Likert scale (i.e., strongly agree, agree, undecided, disagree and strongly disagree). Participants were also asked if they were taught to prevent falls and how to get up after a fall during their rehabilitation stay.

Open-ended questions were used to collect information related to fall prevention strategies they intended to make or already had made in order to prevent falls. The responses were categorized using the work of Hill et al. [14] into one of the following seven categories: 
behavioural, support while mobilizing (use of supportive equipment or items), approach to movement (moving in a particular manner), physical environment (modifications of their physical home environment), medical (strategies that influenced medical conditions) and activity and exercise.

\section{Data Analysis}

Participant demographics and responses to the questionnaire were summarized using means and standard deviations or frequencies and percentages, as appropriate. Data from the questionnaire provided frequencies, continuous variables and written responses. Paired ttests were used to analyze data between discharge and follow-up for the total Activitiesspecific Balance Confidence scale, each of the 13 falls risk factors as well as the four themes of falls risks factors. Frequency variables in the falls prevention strategies subsection were analyzed using a Chi-square test.

The responses to the two open-ended falls prevention questions were analyzed through open coding, where separate individual strategies were identified [14]. The strategies were categorized independently into the seven categories previously defined by two of the authors and any disagreements were resolved by consensus. The number of responses in each category was quantified and this was used to determine the most common type of intervention. Intervention categories were further broken down to identify specific strategies that were commonly listed.

Significance level was set to $\mathrm{p}<0.05$ for all analyses. All analysis was performed with SPSS for Windows (V 24.0, SPSS Inc., Chicago, IL).

\section{Results}

\section{Descriptive Characteristics}


Thirty individuals with a lower extremity amputation were recruited and enrolled in this study. Of these individuals, three did not attend the 4-months appointment: 2 were lost to follow-up and one was deceased. Data from the remaining 27 participants were analyzed. (Table 1) Comorbidities were common in this cohort, particularly vascular morbidities including: hypertension (63.0\%), diabetes (74.1\%) and dyslipidemia (44.4\%).

\section{Falls}

At discharge, two (7.4\%) participants reported falling during the course of their rehabilitation stay. Both individuals were wearing their prosthesis at the time of their fall; neither were injured, but one reported that the fall affected their confidence. Only $2(7.4 \%)$ participants reported that fear of falling affected their daily activities at time of discharge.

At follow-up, eight (29.2\%) participants reported falling in the four months after returning to home; only two (25.0\%) were wearing their prosthesis for the fall. This was a $22.0 \%$ increase in number of falls compared to discharge. Three individuals (37.5\%) were injured by the fall, but only one sought medical attention. Seven participants (25.9\%) reported that fear of falling affected their daily activities.

\section{Activities-specific Balance Confidence Scale}

The total Activities-specific Balance Confidence scale were 67\% at discharge and $63 \%$ at follow-up; these were not significantly different $(\mathrm{p}=0.404)$. At discharge, participants reported the highest confidence in the following activities: reaching for a small can at eye level $(94.1 \pm 9.3 \%)$, walking outside the house to a car parked in a driveway (89.3 $\pm 12.4 \%)$ and getting into or out of a car $(94.1 \pm 7.5 \%)$. These three activities were also reported to have the highest confidence at follow-up, with scores of $89.6 \pm 20.1 \%, 81.1 \pm$ 
$31.4 \%$ and $91.5 \pm 19.9 \%$ respectively. A complete breakdown of responses to the Activitiesspecific Balance Confidence scale is shown in Figure 1.

\section{Knowledge of Risk Factors}

At discharge, participants estimated that $53 \pm 24.1 \%$ of people with a lower extremity amputation would fall in the 12 months following discharge. However, a majority of participants $(88.9 \%)$ believed that falls could be prevented in the lower extremity amputation population. There were no statistically significant changes in how participants rated the individual factors for increasing falls risk between discharge and follow-up $(\mathrm{p}=0.361)$.

(Figure 2) Additionally, when the questions were grouped into four previously mentioned themes, there was no statistically significant difference between discharge and follow-up. Participants rated unsafe or risky behaviours $\left(t_{1}=82.6 \pm 18.1, t_{2}=81.9 \pm 18.4\right)$, not paying attention to surroundings $\left(\mathrm{t}_{1}=76.3 \pm 23.6, \mathrm{t}_{2}=79.3 \pm 20.2\right)$ and sidewalks/streets not cleared of snow and ice $\left(\mathrm{t}_{1}=74.4 \pm 34.7, \mathrm{t}_{2}=81.9 \pm 20.2\right)$ as the top three risk factors. The three lowest risk factors were a prosthesis causing balance and coordination problems $\left(\mathrm{t}_{1}=50.0+/-\right.$ $\left.27.7, \mathrm{t}_{2}=49.3+/-30.9\right)$, forgetfulness $\left(\mathrm{t}_{1}=51.5+/-31.2, \mathrm{t}_{2}=54.8+/-30.4\right)$, and rugs and furniture $\left(\mathrm{t}_{1}=55.9+/-35.1, \mathrm{t}_{2}=55.6+/-30.2\right)$.

\section{Falls Prevention Strategies}

When compared to other health concerns, the importance of falls and fall prevention was rated as $7.6 \pm 2.2$ out of 10 . Scores ranged from two to ten, indicating that all participants valued falls and falls prevention to some degree. Six (22.2\%) participants reported falls and falls prevention as their most important health concern.

At discharge, $21(77.8 \%)$ participants believed they would fall at some point in the 12 months following discharge from rehabilitation. This number fell to $10(37.0 \%)$ at four 
months follow-up. Most participants strongly agreed or agreed $(n=19,70.4 \%)$ that they would be seriously injured if they fell hard. Participants also reported that they strongly agreed or agreed $(n=19,70.4 \%)$ that they would be able to return to their current living situation if they fell hard. A majority of participants $(96.3 \%)$ remembered being taught how to prevent falls and slightly less $(85.2 \%)$ recalled being instructed on how to get up after a fall.

A total of 85 modifications were reported by participants. The average number of modifications was $2.8 \pm 1.6$. These modifications ranged from minimal (e.g., moving phone charger location for easier access) to more extreme (e.g., moving to a more accessible housing unit). The number of responses in each category were: physical environment ( $\mathrm{n}=68$, $80.0 \%)$, support while mobilizing $(\mathrm{n}=6,7.1 \%)$, behavioural $(\mathrm{n}=5,5.9 \%)$, approach to movement $(n=5,5.9 \%)$, medical $(n=1,1.2 \%)$, and activity and exercise $(0 \%)$.

The most common physical environment modifications were installing grab bars/railings (33.8\%) and decreasing obstacles by clearing clutter, rearranging furniture or removal of rugs $(19.1 \%)$. Other physical modifications included installing chair lifts (7.4\%) and ramps (2.9\%). In support while mobilizing, a majority (83.3\%) listed using a walker, cane or other supportive device. Of the five behavioural modifications listed, $3(60.0 \%)$ consisted of awareness, $1(20.0 \%)$ consisted of halting risky behaviour and $1(20.0 \%)$ slowing down in general. Approach to movement modifications included: $1(20.0 \%)$ ensuring balance before participating in an activity, $1(20.0 \%)$ using caution navigating tight spaces, $1(20.0 \%)$ caution with transfers and bathrooms, 1 (20.0\%) use of ramps instead of stairs, and $1(20.0 \%)$ mindfulness of counters. One visual modification was listed under medical: 'looking for supportive elements in case they are needed'. 


\section{Discussion}

This study has demonstrated that there was no change in knowledge of falls risk factors and fall prevention strategies for individuals with a lower extremity amputation between discharge and 4 months after returning home from inpatient prosthetic rehabilitation. Importantly, individuals with lower extremity amputation considered falls to be preventable and ranked falls/fall prevention as an important health concern. This study also demonstrated the vast range in perceptions surrounding known falls risk factors, which highlights a disconnect between knowledge of falls risk factors and application of knowledge to prevent falls. This is the first study the authors are aware of that has looked at falls prevention knowledge and implementation of prevention strategies among older adults with lower extremity amputation.

Participants in this study believed that although they may be seriously injured by a fall, this injury would not impact their current living situation. They had an understanding of the negative consequences that falls may have on their health, but these consequences were not transferred to their environment. Braun et al. [9] found similar results in a population of older adults; they concluded that while participants appear to have an understanding of the effects of falls on health, they underestimate the personal consequences of falling. In comparison to the older adults in Braun et al. [9], individuals with a lower extremity amputation perceive falls and falls prevention as more important to their health.

The falls risk factors presented on the questionnaire are well established, as such it was expected that participants would rank all of them quite highly. The low average risk scores imply that participants underestimate or are unaware of the link between these factors and falls. The highest perceived risk factors were behavioural, yet paradoxically, behavioural 
modifications represented a very small fraction of falls prevention modifications employed by the participants. Importantly, the participants ranked the presence of the prosthesis as the lowest factor leading to the occurrence of falls. This study demonstrates a divide between what participants acknowledge as a falls risk factor and what may prevent them from falling.

The largest group of reported falls prevention modifications was environmentalbased; this may be explained by the home safety assessments that were performed as part of the rehabilitation program, which would reinforce the need for environmental modifications. Additionally, within our healthcare system public funding is available for equipment needs that are prescribed by physical and occupational therapists (such as mobility aids and grab bars) for the person's return to their home setting. Research recommends physical activity as a method of falls prevention in older adults, however no such modification was listed by participants in the current study $[14,15]$. This may be a target for future fall prevention programming in those with lower extremity amputation.

Scores on the Activities-specific Balance Confidence scale demonstrated that balance confidence did not change over the duration of the study. However, at follow-up fewer participants had an expectation of falling within the next year compared to discharge. This may indicate that participants became more confident in their ability to complete normal daily activities without falling, yet the Activities-specific Balance Confidence scale may not accurately represent all aspects of balance confidence for the lower extremity amputation population. Previous research with experienced lower extremity amputation prosthetic ambulators reported slightly higher values for the Activities-specific Balance Confidence scale [16], however this difference may be related to the difference in length of time using their prosthesis and age groups between the two studies. Specifically, Frengopoulos et al. 
[16] included people aged 18 years and older who were successful community ambulators with their prosthesis, while our study was limited to people older than 50 years of age who were newly learning to ambulate with their prosthesis. The scores in our study were $67 \%$, previous research in community-dwelling older adults found scores less than $80 \%$ indicated an increased risk of falling and may require an intervention to prevent falls [17]. A threshold value for the Activities-specific Confidence Scale that indicates an increased risk of falling has not been established in the lower extremity amputee population.

The main limitation of this study is the sample size which may lead to the results being underpowered to find statistically significant differences. Another potential limitation was the 4-months follow-up time frame; it may not have been a long enough to yield a change in balance confidence scores. More time may be required for individuals to engage in a greater range of activities that facilitate increased confidence. We would also like to highlight that the participants included in the study are an older demographic with a greater burden of comorbidities and unique issues related to the majority who had dysvascular etiology for the amputation which is associated with an increased risk of falls and therefore the results are not generalizable to all lower extremity amputees. We also quantified falls through self-report, though this method of falls ascertainment has the potential for individuals to under-report fall occurrences the short duration for the study should limit forgetting compared to a longer time of reference.[18] However, the study does have several strengths. It is the first study to evaluate falls risk factor knowledge and falls prevention strategies among people with a lower extremity amputation, providing valuable information that can be used to inform fall prevention education strategies. All people who were eligible for the study during the recruitment time 
frame were enrolled in the study, therefore the data is representative of the patient profile seen in our institution. This may not be representative of other centres.

\section{Conclusion}

Falls and falls prevention is perceived as an important health outcome by older adults with a lower extremity amputation. However there are gaps in knowledge, especially with regard to application of knowledge of falls risk factors for preventing falls. The current study indicates the need for rehabilitation programs to encourage all forms of falls prevention modifications in order to address these risk factors. Further studies are needed to support these findings and inform whether changes to current practices are needed.

\section{Declaration of Interest Statement}

The authors report no conflicts of interest.

\section{Implications for Rehabilitation:}

- Falls and fall prevention are an important health concern for those with lower extremity amputations and should be addressed during the rehabilitation process.

- Balance confidence among individuals with lower extremity amputations is low, indicating that this population is at an increased falls risk and may require intervention to prevent falls.

- Rehabilitation programs should encourage all forms of falls prevention modifications and strategies, such as behavioural modifications, physical activity and environmental modifications.

- There is a gap between knowledge of falls risk factors and how to apply this to prevent falls, which may be a target for rehabilitation. 


\section{References}

[1] Summary of the Updated American Geriatrics Society/British Geriatrics Society Clinical Practice Guideline for Prevention of Falls in Older Persons. J Am Geriatr Soc 2011;59:148-57. doi:10.1111/j.1532-5415.2010.03234.x.

[2] Kulkarni J, Toole C, Hirons R, Wright S, Morris J. Falls in patients with lower limb amputations: Prevalence and contributing factors. Physiotherapy 1996;82:130-6. doi:10.1016/S0031-9406(05)66968-4.

[3] Hunter S, Batchelor F, Hill K, Hill A, Mackintosh S, Payne M. Risk factors for falls in people with a lower extremity amputation: a systematic review. PM\&R 2016:doi:10.1016/j.pmrj.2016.07.531.

[4] Dite W, Connor HJ, Curtis HC. Clinical Identification of Multiple Fall Risk Early After Unilateral Transtibial Amputation. Arch Phys Med Rehabil 2007;88:109-14. doi:10.1016/j.apmr.2006.10.015.

[5] Jorgensen L, Engstad T, Jacobsen B. Higher incidence of falls in long-term stroke survivors than in population controls. Stroke 2002;33:542-7.

[6] Miller WC, Deathe AB. The influence of balance confidence on social activity after discharge from prosthetic rehabilitation for first lower limb amputation. Prosthet Orthot Int 2011;35:379-85. doi:10.1177/0309364611418874.

[7] Miller WC, Deathe AB, Speechley M, Koval J. The influence of falling, fear of falling, and balance confidence on prosthetic mobility and social activity among individuals with a lower extremity amputation. Arch Phys Med Rehabil 2001;82:1238-44. doi:10.1053/apmr.2001.25079.

[8] Miller WC, Speechley M, Deathe B. The prevalence and risk factors of falling and 
fear of falling among lower extremity amputees. Arch Phys Med Rehabil 2001;82:1031-7. doi:10.1053/apmr.2001.24295.

[9] Braun BL. Knowledge and perception of fall-related risk factors and fall-reduction techniques among community-dwelling elderly individuals. Phys Ther 1998;78:126276.

[10] Nasreddine ZS, Phillips NA, Bedirian V, Charbonneau S, Whitehead V, Collin I, et al. The Montreal Cognitive Assessment, MoCA: A brief screening tool for mild cognitive impairment. J Am Geriatr Soc 2005;53:695-9. doi:10.1111/j.1532-

5415.2005.53221.x.

[11] Lamb SE, Jorstad-Stein EC, Hauer K, Becker C. Development of a Common Outcome Data Set for Fall Injury Prevention Trials: The Prevention of Falls Network Europe Consensus. J Am Geriatr Soc 2005;53:1618-22. doi:10.1111/j.15325415.2005.53455.x.

[12] Powell LE, Myers AM. The Activities-Specific Balance Confidence (ABC) Scale. J Gerontol Med Sci 1995;50A:M28-34.

[13] Miller WC, Deathe AB, Speechley M. Psychometric properties of the activitiesspecific balance confidence scale among individuals with a lower-limb amputation. Arch Phys Med Rehabil 2003;84:as0003999303048074. doi:10.1016/S00039993(03)04807-4.

[14] Hill AM, Hoffmann T, Beer C, McPhail S, Hill KD, Oliver D, et al. Falls after discharge from hospital: Is there a gap between older peoples' knowledge about falls prevention strategies and the research evidence? Gerontologist 2011;51:653-62. doi:10.1093/geront/gnr052. 
[15] Gillespie LD, Robertson MC, Gillespie WJ. Interventions for preventing falls in older people living in the community. Cochrane Database Syst Rev 2013;2:CD007146.

[16] Frengopoulos C, Payne MW, Holmes JD, Viana R, Hunter SW. Comparing the Effects of Dual-task Gait Testing in New and Established Ambulators with Lower Extremity Amputations. PM\&R 2018. doi:10.1016/j.pmrj.2018.03.018.

[17] Myers a M, Fletcher PC, Myers a H, Sherk W. Discriminative and evaluative properties of the activities-specific balance confidence (ABC) scale. J Gerontol A Biol Sci Med Sci 1998;53:M287-94. doi:10.1093/gerona/53A.4.M287.

[18] Ganz DA, Higashi T, Rubenstein LZ. Monitoring Falls in Cohort Studies of Community-Dwelling Older People: Effect of the Recall Interval. J Am Geriatr Soc 2005;53:2190-4. doi:10.1111/j.1532-5415.2005.00509.x. 
Table 1. Demographic and clinical characteristics of older adults with major unilateral lower extremity amputation at discharge from prosthetic rehabilitation. $(n=27)$

\begin{tabular}{|l|l|}
\hline \multicolumn{1}{|c|}{ Variables } & \multicolumn{1}{|c|}{ Mean \pm SD or Frequency (\%) } \\
\hline Age (years) & $15(55.6 \%)$ \\
BMI (kg/m $\left.{ }^{2}\right)$ & $29.05 \pm 6.43$ \\
Years of Education & $12.9 \pm 2.6$ \\
Level of amputation (n, \% below knee) & $21(77.8 \%)$ \\
Primary Etiology of Amputation (n, \%): & $17(63.0 \%)$ \\
DM & $5(18.5 \%)$ \\
PVD & $1(3.7 \%)$ \\
DM+PVD & $4(14.8 \%)$ \\
Other (trauma, cancer, infection) & $5.3 \pm 2.2$ \\
Number of Comorbidities & $10.6 \pm 5.1$ \\
MoCA Score & $25.7 \pm 2.8$ \\
\hline
\end{tabular}

Note: BMI, Body Mass Index; DM, Diabetes Mellitus; PVD, Peripheral vascular disease; MoCA, Montreal Cognitive Assessment 


\section{$\underline{\text { Figure Captions }}$}

Figure 1. Responses to the Activities-specific Balance Confidence Scale from older adults with major lower extremity amputation at discharge from inpatient prosthetic rehabilitation and at 4-months follow-up $(\mathrm{n}=27)$.

Figure 2. Knowledge of risk factors for falls among older adults with major unilateral lower extremity amputation at discharge from inpatient prosthetic rehabilitation and at 4-months follow-up ( $\mathrm{n}=27)$. 
Figure 1.

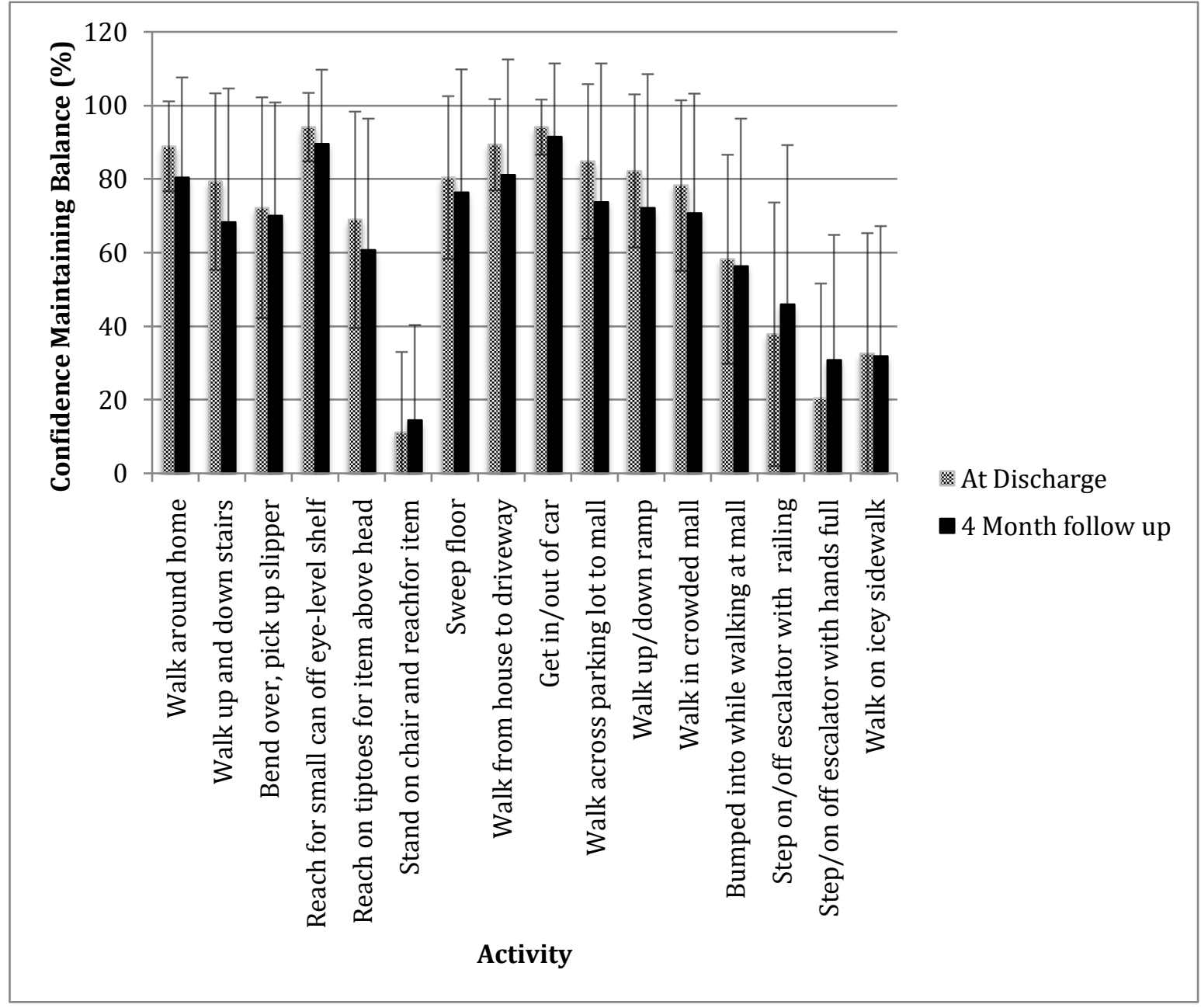


Figure 2.

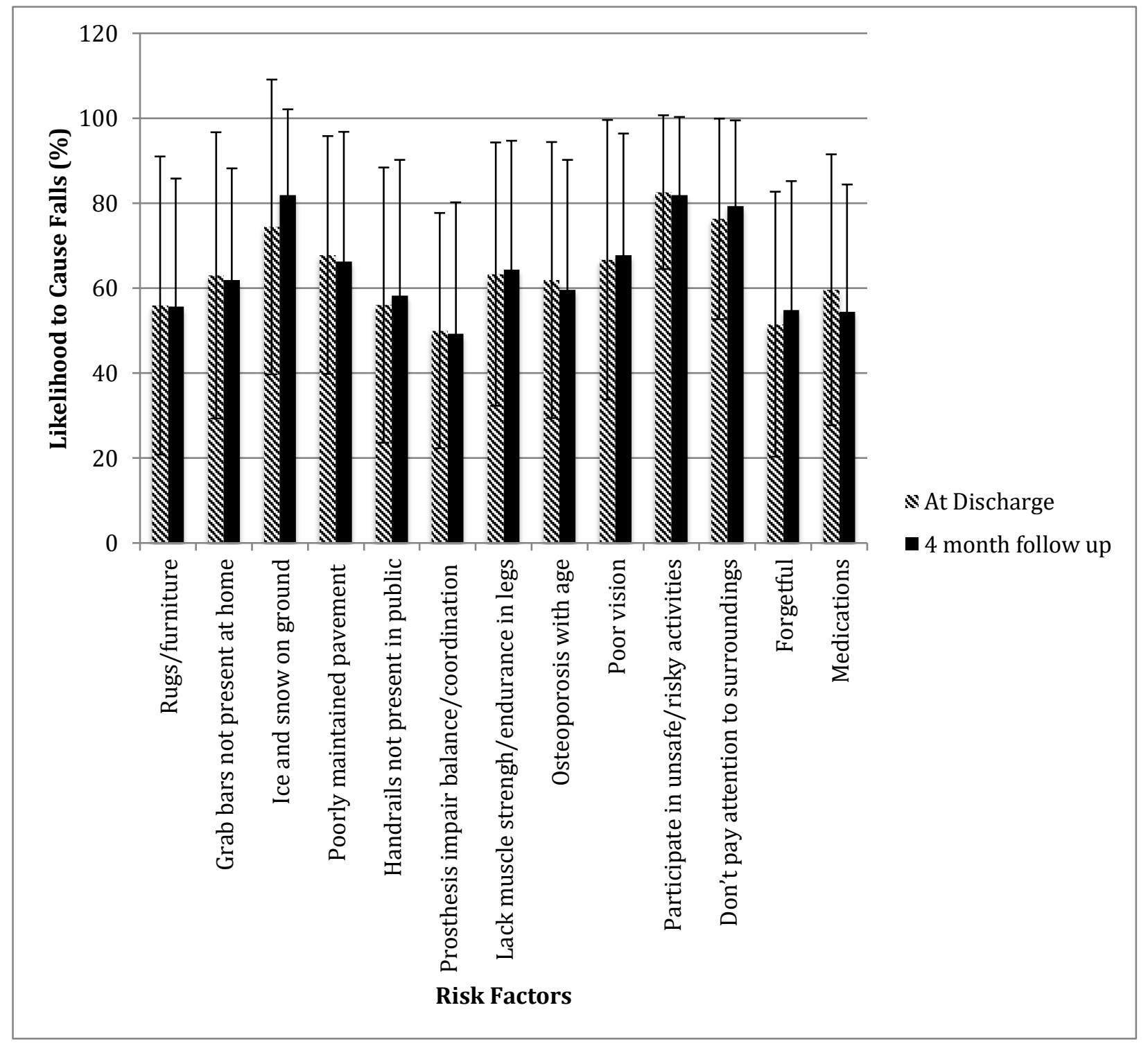




\section{Appendix A.}

LOWER EXTREMITY AMPUTEE FALLS PREVENTION SURVEY

Thank you for agreeing to take part in this important survey measuring issues related to fall prevention for people who have completed inpatient rehabilitation in the Amputee Program at Parkwood Institute. Through completing this survey, your answers will be helpful in improving our understanding of falls and the content of the program to address fall prevention for future clients in the program. The survey will take approximate 30 minutes to complete. Be assured that all answers you provide will be kept in strictest confidence

\section{Section 4. Falls}

The following questions ask about any falls you may have had during the time of your rehabilitation at Parkwood Institute.

1. Did you fall during the time of your rehabilitation stay at Parkwood Institute? This includes falls actually on site at Parkwood Institute or during any weekend/weekday passes from rehabilitation at Parkwood Institute.

$\square$ Yes (Go to Question \#21)

$\square$ No (Go to Question \#27)

2. Did you injure yourself from falling?

$\square$ Yes (Go to Question \#22)

$\square$ No (Go to Question \#24)

3. Where did you injure yourself? (check all that apply)

- Head/neck aYes $\square$ No

- Trunk $\square$ Yes $\square$ No

- Arm $\square$ Yes $\square$ No

- Leg $\square$ Yes $\square$ No

4. Did you seek any medical attention because of the fall(s)?

$\square$ Yes

$\square$ No

The following questions ask about the most recent fall you sustained.

5. Were you wearing your prosthesis when you fell?

$\square$ Yes

$\square$ No

6. Please describe the activity you were doing when you fell.

7. Did the most recent fall affect your confidence?

$\square$ Yes

$\square$ No 
8. Are you afraid of falling, such that you have stopped doing activities you are physically capable of doing?

$\square$ Yes

$\square$ No

For questions 9-24, please indicate your level of confidence in doing an activity without losing your balance or becoming unsteady by choosing one of the percentage points on the scale from $0 \%$ (no confidence) to $100 \%$ (complete confidence). If you do not currently do the activity in question, try and imagine how confident you would be if you had to do the activity. If you normally do the activity using a walking aid or holding onto someone, rate your confidence as if you were using these supports. For each of the following activities, please indicate your level of self-confidence by circling a corresponding number from the rating scale provided.

How confident are you that you will not lose your balance or become unsteady when you...

9. Walk around your home?

$\begin{array}{llllllllll}0 \% & 10 & 20 & 30 & 40 & 50 & 60 & 70 & 80 & 90\end{array}$

10. Walk up or down stairs?

$\begin{array}{llllllllll}0 \% & 10 & 20 & 30 & 40 & 50 & 60 & 70 & 80 & 90 \\ 100 \% & & & & & & & & \end{array}$

11. Bend over and pick up a slipper from the front of a closet floor?

$\begin{array}{llllllllll}0 \% & 10 & 20 & 30 & 40 & 50 & 60 & 70 & 80 & 90 \\ 100 \% & & & & & & & \end{array}$

12. Reach for a small can off a shelf at eye level?

$$
\begin{array}{llllllllll}
0 \% & 10 & 20 & 30 & 40 & 50 & 60 & 70 & 80 & 90 \\
100 \% & & & & & & &
\end{array}
$$

13. Stand on your tiptoes and reach for something above your head?

$$
\begin{array}{llllllllll}
0 \% & 10 & 20 & 30 & 40 & 50 & 60 & 70 & 80 & 90 \\
100 \% & & & & & & &
\end{array}
$$

14. Stand on a chair and reach for something?

$\begin{array}{llllllllll}0 \% & 10 & 20 & 30 & 40 & 50 & 60 & 70 & 80 & 90\end{array}$

15. Sweep the floor?

$\begin{array}{llllllllll}0 \% & 10 & 20 & 30 & 40 & 50 & 60 & 70 & 80 & 90 \\ 100 \% & & & & & & & & \end{array}$

16. Walk outside the house to a car parked in the driveway?

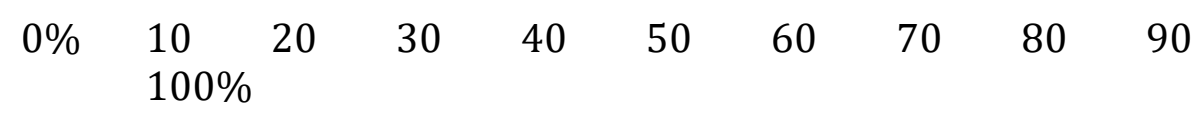


17. Get into or out of a car?

$$
\begin{array}{llllllllll}
0 \% & 10 & 20 & 30 & 40 & 50 & 60 & 70 & 80 & 90 \\
100 \% & & & & & & & &
\end{array}
$$

18. Walk across a parking lot to the mall?

$$
\begin{array}{llllllllll}
0 \% & 10 & 20 & 30 & 40 & 50 & 60 & 70 & 80 & 90 \\
100 \% & & & & & & & &
\end{array}
$$

19. Walk up or down a ramp?

$\begin{array}{llllllllll}0 \% & 10 & 20 & 30 & 40 & 50 & 60 & 70 & 80 & 90 \\ 100 \% & & & & & & & & \end{array}$

20. Walk in a crowded mall where people rapidly walk past you?

$\begin{array}{llllllllll}0 \% & 10 & 20 & 30 & 40 & 50 & 60 & 70 & 80 & 90 \\ 100 \% & & & & & & & & \end{array}$

21. Are bumped into by people as you walk through the mall?

$\begin{array}{llllllllll}0 \% & 10 & 20 & 30 & 40 & 50 & 60 & 70 & 80 & 90 \\ 100 \% & & & & & & & & \end{array}$

22. Step onto or off an escalator while you are holding onto a railing?

$\begin{array}{llllllllll}0 \% & 10 & 20 & 30 & 40 & 50 & 60 & 70 & 80 & 90 \\ 100 \% & & & & & & & & \end{array}$

23. Step onto or off an escalator while holding onto parcels such that you cannot hold onto the railing?

$\begin{array}{llllllllll}0 \% & 10 & 20 & 30 & 40 & 50 & 60 & 70 & 80 & 90 \\ 100 \%\end{array}$

24. Walk outside on icy sidewalks?

$$
\begin{array}{llllllllll}
0 \% & 10 & 20 & 30 & 40 & 50 & 60 & 70 & 80 & 90 \\
100 \% & & & & & & & &
\end{array}
$$

25. At a guess, if you talked to 100 people one year after they had finished their rehabilitation for a prosthesis, how many do you think would have had at least one fall?

26. Do you believe that falls among people with a lower extremity amputation using a prosthesis can be prevented?
Yes
$\square$ No

For questions 27-39, please rate how likely each of these scenarios are in making a person with a lower extremity amputation who uses a prosthesis suffer a fall.

27. They are likely to fall because things such as rugs, furniture?

$$
\begin{array}{llllllllll}
0 \% & 10 & 20 & 30 & 40 & 50 & 60 & 70 & 80 & 90 \\
100 \%
\end{array}
$$


Not at all likely

Most likely

28. They are likely to fall because grab bars are not present or are not in a helpful position in their house or apartment.

$$
\begin{array}{llllllllll}
0 \% & 10 & 20 & 30 & 40 & 50 & 60 & 70 & 80 & 90 \\
100 \% & & & & & & & &
\end{array}
$$

Not at all likely

Most likely

29. They are likely to fall because sidewalks and streets are not clear of ice and snow.

$$
\begin{array}{llllllllll}
0 \% & 10 & 20 & 30 & 40 & 50 & 60 & 70 & 80 & 90
\end{array}
$$

Not at all likely

Most likely

30. They are likely to fall because sidewalks, streets, and pavements are poorly maintained (e.g. cracked or irregular pavement, inadequate street markings).

$$
\begin{array}{llllllllll}
0 \% & 10 & 20 & 30 & 40 & 50 & 60 & 70 & 80 & 90
\end{array}
$$

Not at all likely

Most likely

31. They are likely to fall because handrails are not present or are poorly positioned in public places.

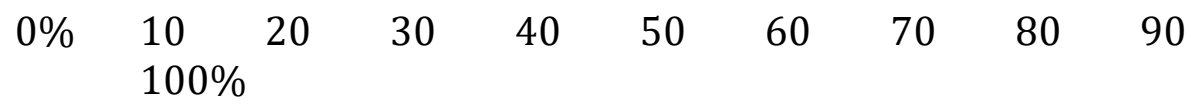

Not at all likely

Most likely

32. They are likely to fall because using the prosthesis can cause a coordination or balance problem.

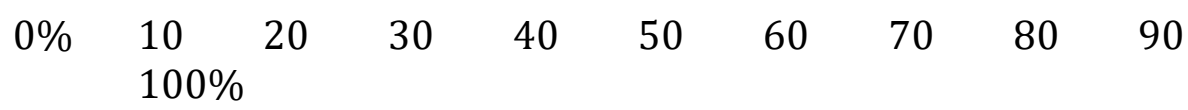

Not at all likely

Most likely

33. They are likely to fall because they do not have enough muscle strength or endurance in their legs.

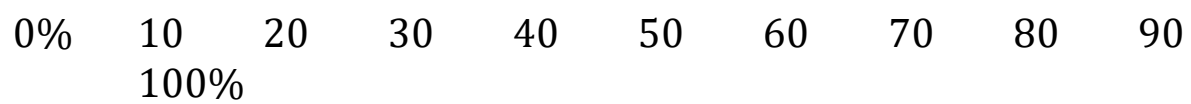

Not at all likely

Most likely

34. They are likely to fall because their bones are weakened with age (osteoporosis).

$\begin{array}{llllllllll}0 \% & 10 & 20 & 30 & 40 & 50 & 60 & 70 & 80 & 90 \\ 100 \% & & & & & & & & \end{array}$


Not at all likely

Most likely

35 . They are likely to fall because they have poor vision.

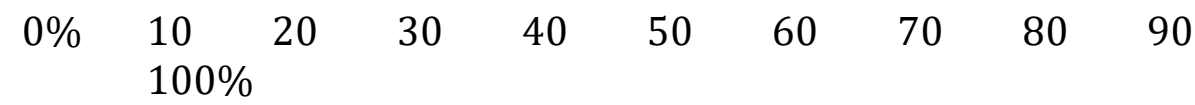

Not at all likely

Most likely

36. They are likely to fall because they do unsafe or risky things.

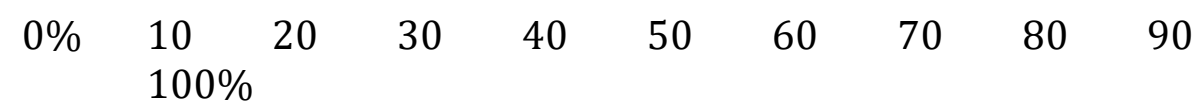

Not at all likely

Most likely

37. They are likely to fall because they do not always pay close attention to their surroundings.

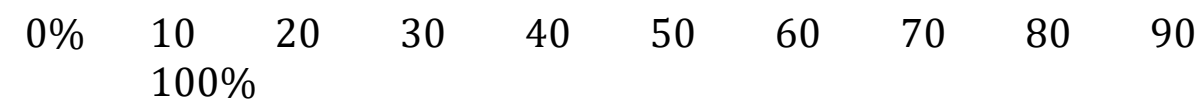

Not at all likely

Most likely

38. They are likely to fall because they are forgetful.

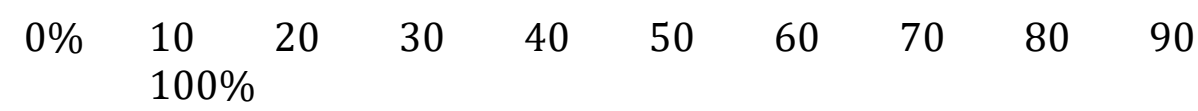

Not at all likely

Most likely

39. They are likely to fall because they take many medications.

$\begin{array}{llllllllll}0 \% & 10 & 20 & 30 & 40 & 50 & 60 & 70 & 80 & 90 \\ 100 \% & & & & & & & & \end{array}$

Not at all likely

Most likely

40. On a scale from 0 to 10 , where 0 means "not at all important" and 10 means

"most important", how important are falls/fall prevention compared with your other health concerns?

Not at all important

$\begin{array}{lllllllllll}0 & 1 & 2 & 3 & 4 & 5 & 6 & 7 & 8 & 9 & 10\end{array}$

Most important

41. Do you think you will fall at some time in the 12 months following your discharge home from rehabilitation?
Yes
No

42. If you fell hard, do you think you would seriously injure yourself? 
Strongly agree Agree $\quad$ Undecided $\quad$ Disagree Strongly disagree

43. If you fell and seriously injured yourself, would you be able to return to your current living situation?

Strongly agree Agree $\quad$ Undecided $\quad$ Disagree Strongly disagree

44. During your inpatient rehabilitation stay, were you taught how to prevent falls?

$\square$ Yes

$\square$ No

45. During your inpatient rehabilitation stay, were you taught how to get up after a fall (i.e., how to get up off the floor)?

$\square$ Yes

$\square$ No

46. Please list any things you have modified in your daily activities and/or home to reduce the risk of falling when you return home after completing your inpatient rehabilitation.

47. Please list any things that you plan to modify in your daily activities and/or home to reduce the risk of falling when you return home after completing your rehabilitation at Parkwood Institute.

48. I am confident I will be able to make the changes I have listed in question \#66.

$$
\begin{aligned}
& \text { Yes } \\
& \text { No }
\end{aligned}
$$

49. Is there something that might make it difficult for you to do the changes you listed in question \#66 are? 
50. I am very keen to lower my risk of falling by using the strategies I listed in question \#66.

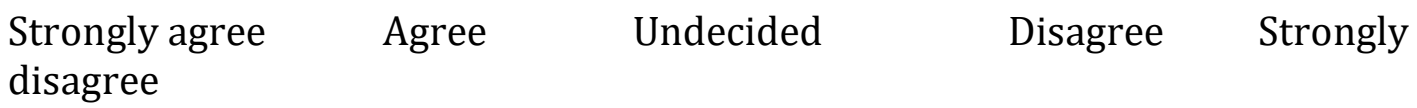

51. I am interested in learning more about how to prevent falls.

\begin{tabular}{|c|c|c|c|}
\hline $\begin{array}{l}\text { Strongly agree } \\
\text { disagree }\end{array}$ & Agree & Undecided & Disagree \\
\hline
\end{tabular}

52. I am very keen to improve my mobility (walking and transfers) after my discharge from rehabilitation.

disagree

Strongly agree Agree Undecided $\quad$ Disagree Strongly

53. I will be participating in an outpatient rehabilitation program after I go home.

Y Yes

$\square$ No

54. Which fall prevention message do you think would be most effective to use for people with a lower extremity amputation?

$\square$ One that highlights the dangers of falling

One that highlights your safety, health and well-being 